\title{
COMO SE CHEGOU AOS VALORES? O PROBLEMA DA JURISPRUDÊNCIA E A INTERPRETAÇÃO DA LEI
}

Vinícius Almada Mozetic

Doutorando em direito pela Universidade do Vale do Rio dos Sinos - UNISINOS; Mestre em direito pela Universidade de Santa Cruz do Sul - UNISC- Direitos Sociais e Políticas Públicas; Professor e Pesquisador do Programa de Pós-Graduação em Direito da Universidade do Oeste de Santa Catarina - UNOESC; Coordenador do curso de Direito da Universidade do Oeste de Santa Catarina - UNOESC e advogado.

\section{Paulo Roberto Ramos Alves}

Doutorando e Mestre em direito pela Universidade do Vale do Rio dos Sinos UNISINOS; professor da Universidade do Oeste de Santa Catarina - UNOESC; advogado.

\section{Resumo}

As normas constitucionais possuem um nível máximo de eficácia, conceitos à lógica valorativa o direito vem experimentando, há décadas, construçôes que buscam evidenciar o fenômeno jurídico ora como um sistema lógico, ora como um sistema que visa à proteção de interesses, ora como um sistema que visa à realização de valores. Em outras palavras, a relação entre direito e moral não aponta para uma neutralidade da moral em relação ao direito, mas evidencia um trânsito de elementos morais via processo legislativo para o interior do direito. Por isso, normas morais são destinadas à regulação de relações interpessoais e normas jurídicas.

\section{Palavras-chave}

Constituição; Jurisprudência; Direito.

\section{Abstract}

The constitutional standards have a maximum level of efficiency, the logic concepts evaluative right has been experiencing for decades, buildings seeking evidence the legal phenomenon or as a logical system, or as a system designed to protect interests, or as a system aimed at the realization values. In other words, the relationship between law and morality does not point to a neutral relation to the moral law, but shows a traffic moral 
elements via legislative process into the law. So, moral norms are intended for regulation of interpersonal relations and legal rules.

\section{Key words}

Constitution; Jurisprudence; Law.

\section{Introdução}

A história legou grandes movimentos que se ocuparam com o problema da interpretação do direito. Da necessidade de integração do direito germânico à consideração de elementos valorativos na decisão judicial, a problemática da interpretação sempre esteve presente, deslocando o centro gravitacional da teoria jurídica conforme a realidade de cada momento histórico.

Da Jurisprudência dos Conceitos à lógica valorativa, o direito vem experimentando, há décadas, construçôes que buscam evidenciar o fenômeno jurídico ${ }^{1}$ ora como um sistema lógico, sistema que visa a proteção de interesses, ora como um sistema que visa a realização de valores.

\section{A Lógica Formal da Jurisprudência dos Conceitos}

A Jurisprudência dos Conceitos emerge do problemático contexto jurídico alemão do século XIX. Com um ordenamento esparso de fontes do direito, carente de ordem ou hierarquia suficientemente clara e precisa, bem como integrado pelo direito das pandectas $^{2}$, o direito positivo alemão apresentava-se extremamente insuficiente e contraditório.

A Jurisprudência dos Conceitos foi a solução encontrada para a integração do ordenamento jurídico, não com base em normas positivas ${ }^{3}$, mas sim por certas categorias conceituais ideais, certos conceitos objetivos aos quais o julgador, ao decidir, deveria observar.

1 Ao "descascarmos" o fenômeno, este aparece(rá) como "ele é", em sua historicidade e sua faticidade. Enfim, hermenêutica não é método por uma razão singela: é impossível responder à pergunta acerca de qual é o método que existe para dizer o método adequado para interpretar...Isso está muito claro desde há muito, tanto em Gadamer como no pai do pós-positivismo, Friedrich Müller. In: Streck, Lenio Luiz Jurisdição constitucional e decisão jurídica / Lenio Luiz Streck. - São Paulo : Editora Revista dos Tribunais, 2013.

2 Cf. CORPUS IURIS CIVILIS. DIGESTORUM SEU PANDECTARUM PARS PRIMA. LIBER PRIMUS. (Corpo de Direito Civil. Primeira Parte do Digesto ou das Pandectas. Primeiro Livro)(30 de Dezembro de 533), in : Corpus Iuris Civilis, Recognovit Paul Krueger / Theodor Mommsen, Berlim Hildesheim : Weidmann, 1872, Vol. 1, pp. 3 e s.

3 Sobre a sistematização do ordenamento jurídico e sua integração em uma rede normativa hierarquizada ver KELSEN, Hans. Teoria pura do direito. São Paulo: Martins Fontes, 2000. 
Tendo em vista o problema da integração do ordenamento jurídico, bem como a recorrente necessidade de sistematização da ciência do direito, a Jurisprudência dos Conceitos, pelas mãos de Georg Friedrich Puchta, transforma o discurso jurídico em um sistema conceitual lógico, piramidalmente hierarquizado, culminando em uma construção dotada de extrema subjetividade ${ }^{4}$.

Dessa forma, a Jurisprudência dos Conceitos surge como a possibilidade de consolidação de um conhecimento jurídico sistemático, dando-se tal sistematização por meio da vinculação dos componentes do sistema jurídico a uma conceituação unitária. Essa construção pressupóe que todos os elementos conceituais provêm de uma mesma fonte, de um conceito supremo que delimita todos os demais.

Com base em uma noção de sistema e de um critério próprio de racionalidade, a Jurisprudência dos Conceitos procura demonstrar a operacionalidade jurídica por meio de uma pirâmide conceitual, onde em seu topo há o conceito com maior nível de generalização, a partir do qual são subsumidos todos os subjacentes. Dessa forma, os conceitos derivados sempre reportam ao originário, viabilizando, assim, um sistema de regras lógico-formal extremamente funcional, sem contradiçôes e sem lacunas ${ }^{5}$.

O problema central para a Jurisprudência dos Conceitos foi justamente a localização de um princípio que fosse de tal modo geral e omniabarcador onde pudesse deduzir, a partir dele, todos os demais conceitos jurídicos ${ }^{6}$. Desse modo, todo o direito necessariamente faria referência a tal conceito supremo, decorrendo daí toda a possibilidade de aplicação do direito ao caso concreto.

Assim, a Jurisprudência dos Conceitos é fundada na ideia de interpretação mecanicista do direito, isto é, prega que para uma dada situação e um dado conjunto de normas jurídicas, há um, e somente um resultado possível, dado pela ciência jurídica e por conceitos previamente extraídos da norma, independente da subjetividade do intérprete, sendo que tal construção demonstra grandes fragilidades.

A Jurisprudência dos Conceitos pode ser compreendida como um mecanismo de limitação ao julgador à mera subsunção da matéria fática a conceitos jurídicos predeterminados, compreendendo-se o direito como um discurso sistemático.

\subsection{O Jusliberalismo do Movimento do Direito Livre}

O Movimento do Direito Livre caracterizou-se justamente pela ação contrária à hierarquização lógico-formal da Jurisprudência dos Conceitos. Contrariamente a um

4 KRETSCHMANN, Ângela. História critica do sistema jurídico: da prudência antiga à ciência moderna. Rio de Janeiro: Renovar, 2006. p. 181.

5 KAUFMANN, Arthur; HASSEMER, Winfried (Org.). Introdução à filosofia do direito e à teoria do direito contemporâneo. Lisboa: Fundação Calouste Gulbenkian, 2002. p. 168.

6 LOSANO, Mario Giuseppe. Sistema e estrutura no direito. Volume 1: Das origens à escola histórica. São Paulo: Martins Fontes, 2008. p. 338. 
fechamento conceitual do sistema jurídico, o Movimento do Direito Livre preconizava que toda a decisão judicial não era a mera aplicação da lei vigente, mas igualmente um processo jurídico (livre) direcionado à criação do direito.

Para essa escola, a lei não seria capaz de criar o direito de forma completa, sendo que esta se afiguraria apenas como o início do caminho da construção da ordem jurídica. Durante as primeiras três décadas do século XX, o pensamento jurídico se caracteriza pela constante oposição a entre rigidez e certeza do direito - próprias da pandectística da Jurisprudência dos Conceitos. - e a flexibilidade da decisão individual.

Assim, a tônica do discurso jusliberalista centra-se justamente no problema das lacunas do direito, deslocando o centro gravitacional do debate sobre um pretenso - e completo - sistema jurídico para o reconhecimento da ampla existência de lacunas jurídicas e sobre o papel do julgador frente a tais problemas não regulamentados pela norma ${ }^{7}$.

\subsection{A Teleologia da Jurisprudência dos Interesses}

Frente às nítidas insuficiências da jurisprudência conceitualista, surge, na primeira metade do século XX, a chamada Jurisprudência dos Interesses. Nitidamente influenciada pelo pela segunda fase do pensamento de Ihering ${ }^{8}$, a escola dos interesses desenvolve-se pelas mãos de Philipp Heck, o qual se insurgirá contra a metodologia lógico-formal conceitualista, denunciando que a tarefa do juiz limitava-se à mera atividade gnosiológica, havendo meramente a subsunçáo do caso concreto e, com isso, sendo negado o potencial criador do direito?.

A Jurisprudência dos Interesses surge a partir do reconhecimento dos nítidos problemas apresentados pela Jurisprudência dos Conceitos, bem como pela necessidade de equilibrar rigorosas exigências formalistas e ideais sociológicos.

Já no início de sua Interpretação da lei e Jurisprudência dos Interesses, Heck insurge-se contra a problemática da corrente conceitualista, quando afirma que a teoria citada já não

7 LOSANO, Mario Giuseppe. Sistema e estrutura no direito. Volume 2: O século XX. São Paulo: Martins Fontes, 2010. p. 158-159.

8 A segunda fase da teorização de Rudolph von Ihering é justamente caracterizada pelo reconhecimento de que o direito necessariamente vincula-se à um fim social, o que conduz à observações sobre o direito sob um viés sociologizante. Vide IHERING, Rudolf von. El fin en el derecho. Pamplona: Anacleta, 2005. p. 8: "Um ato de vontade sem causa final é um impossível tão absoluto como o movimento de uma pedra sem causa eficiente. Tal é a lei da causalidade: psicológica no primeiro caso, puramente mecânica no segundo. Para abreviar, chamarei desde logo a primeira de finalidade, para indicar assim, por seu mesmo nome, que a causa final é a única razão psicológica da vontade. Enquanto à lei de causalidade mecânica, o termo lei de causalidade bastará para designá-la daqui a diante. Esta lei, neste último sentido, pode explicar-se assim: nenhuma acontecimento se produz no mundo físico sem um acontecimento anterior no qual encontra sua causa. É a expressão habitual: não há efeito sem causa. A lei de finalidade diz: não há ação sem causa”.

9 HECK, Philipp. El problema de la creación del derecho. Granada: Comares, 1999. p. 21. 
encontra defensores e cada vez mais conta com posiçóes favoráveis à uma ampliação da liberdade interpretativa dos juízes. ${ }^{10}$ Baseando-se em uma metodologia histórica, Heck aponta para a necessidade de formas interpretativas que levem em consideração os interesses do legislador quando da promulgação de determinada lei.

Essa interpretação histórico-teleológica aponta para o fato de que o julgador "deve procurar sim os pensamentos exteriorizados ou revelados por meio do acto legislativo, mas a sua acção retrospectiva deve ir mais longe, até os interesses determinantes da lei, aos interesses causais" 11 .

Ao utilizar a expressão vontade do legislador, Heck demonstra que:

[...] a expressão vontade não aponta para critérios psicológicos, mas sim para horizontes de interesses causais, sendo a vontade um conceito normativo na medida em que exprime determinados interesses do legislador. Os comandos legislativos, por isso, caracterizam-se sob uma dupla face, eis que se destinam a resolver problemas de interesses e, igualmente, apresentam-se como produtos de interesses. Isso significa que todos os comandos legais vigentes são produtos de interesses que se originam em determinada comunidade, sejam eles de ordem religiosa, política, ética, etc ${ }^{12}$.

Portanto, o centro gravitacional da Jurisprudência dos Interesses se dá justamente a partir da decisão do legislador, vinculando-se à sua vontade enquanto fator causal de interesses.

\subsection{Tribunal Constitucional Federal Alemão e Jurisprudência dos Valores}

A fronteira entre a Jurisprudência dos Interesses e a Jurisprudência dos Valores se dá justamente a partir da impossibilidade de visualização daquele interesse que historicamente moveu o legislador. Logo, a Jurisprudência dos Valores passa a integrar a Jurisprudência dos Interesses, buscando apontar a origem dos valores que norteiam a decisão judicial nos momentos em que a norma, por si só, não é capaz de fornecer critérios para a avaliação do caso concreto ${ }^{13}$.

Após a segunda grande guerra, principalmente por influência da Declaração Universal dos Direitos do Homem, o mundo jurídico passa a observar a crescente construção de um movimento jurídico fundado no reconhecimento de uma ordem valorativa, espelhada por um pretenso arcabouço de valores presentes nas Constituiçóes. A doutrina dos valores

10 HECK, Philipp. Interpretação da lei e jurisprudência dos interesses. São Paulo: Saraiva, 1947. p. 5.

11 HECK, Interpretação da lei e jurisprudência dos interesses, p. 10.

12 HECK, Interpretação da lei e jurisprudência dos interesses, p. 19.

13 LOSANO, Sistema e estrutura no direito. v. 2, p. 252. 
desenvolve-se na Alemanha, justamente a partir do segundo pós-guerra., pela atuação do Tribunal Constitucional Federal alemão.

É interessante ressaltar que essa corrente serviu igualmente para legitimar a Lei Fundamental (Grundgesetz) alemã de 1949, eis que a Carta não fora constituída mediante a ampla participação do povo, conforme demonstra Streck quando explica os esforços do BverfG para possibilitar uma abertura do direito frente a uma estrutura normativa extremamente fechada:

[...] a Jurisprudência dos Valores serviu para equalizar a tensão produzida depois da outorga da Grundgesetz pelos aliados, em 1949. Como efeito, nos anos que sucederam à consagraçáo da lei fundamental, houve um esforço considerável por parte do Bundesverfassungsgericht para legitimar uma carta que náo tinha sido construída pela ampla participação do povo alemão. Daí a afirmação de um jus distinto da lex, ou seja, a invocação de argumentos que permitissem ao Tribunal recorrer a critérios decisórios que se encontravam fora da estrutura rígida da legalidade. A referência a valores aparece, assim, como mecanismo de "abertura" de uma legalidade extremamente fechada ${ }^{14}$.

O Tribunal Constitucional Federal alemão, dessa maneira, serviu como um meio legitimador da Lei Fundamental no período do segundo pós-guerra. Conforme demonstra Streck, a Jurisprudência dos Valores conta justamente com a invocação de argumentos que ultrapassem o rígido limite da legalidade, trazendo à prática jurídica a possibilidade de abertura interpretativa a partir de um arcabouço valorativo próprio da Constituição. E é justamente sobre a doutrina valorativa elaborada pelo Tribunal Constitucional Federal alemáo que recai a atual insurgência teórica de Jürgen Habermas.

A teoria habermasiana se insurge justamente contra essa tendência a uma concretização de valores constitucionais. O direito moderno, para Habermas, se caracteriza precisamente pela possibilidade democrática. Baseado em um princípio discursivo-procedimental (democrático), o herdeiro intelectual da Escola de Frankfurt conceberá um sistema jurídico dependente de uma situação discursiva ideal, sob a qual é assentada a possibilidade de uma prática não fundamentada em argumentos morais, mas na necessária liberdade e igualdade de todos os participantes do discurso jurídico, o que, por certo, apenas é possível em um ambiente democrático.

Por sua vez, a validade do direito relaciona-se com o arbítrio Estatal. Ao defender a democracia, Habermas entende que a validade dos procedimentos jurídicos depende de níveis de autonomia do sujeito de direito, bem como da harmonização entre soberania popular e direitos humanos. Habermas.

14 STRECK, Lenio Luiz. Verdade e consenso. 4. ed. São Paulo: Saraiva, 2011. p. 48. 
[...] entende que tanto as normas jurídicas como as normas morais tratam-se de normas de ação, sendo que tais normas referem-se aos mesmos problemas, todavia, ângulos distintos. Mesmo havendo pontos em comum, direito e moral distinguem-se em razão de que a moral representa uma forma do saber cultural, enquanto o direito torna-se obrigatório a partir de sua inserção no nível institucional ${ }^{15}$.

Em outras palavras, a relação entre direito e moral não aponta para uma neutralidade da moral em relação ao direito, mas evidencia um trânsito de elementos morais, via processo legislativo para o interior do direito. A relação de complementariedade entre direito e moral aponta para a co-originariedade entre tais âmbitos normativos, isto é, preceitos morais ingressam na ordem jurídica no momento da promulgação de determinada lei.

O legislador internaliza preceitos morais quando os considera para a proposição de determinado comando jurídico-normativo. Isso significa que os preceitos morais ingressam no direito, porém, no momento em que passam a integrar a norma jurídica, não se pode mais falar em moral (tampouco em fundamento moral), mas tâo somente em direito. Dessa relação de complementariedade depende a própria legitimidade do direito. Para Habermas:

[...] uma ordem jurídica só pode ser legítima quando não contrariar princípios morais. Através dos componentes da legitimidade e da validade jurídica, o direito adquire uma relação com a moral. Entretanto, essa relação não deve levar-nos a subordinar o direito à moral, no sentido de uma hierarquia de normas. A ideia de que existe uma hierarquia de leis faz parte do mundo pré-moderno do direito. A moral autônoma e o direito positivo, que depende de fundamentação, encontram-se numa relação de complementação recíproca ${ }^{16}$.

Por isso, normas morais são destinadas à regulação de relações interpessoais e conflitos entre pessoas naturais que se reconhecem como membros de uma comunidade concreta, dirigindo a vida individualmente, conforme sua história de vida. Normas jurídicas, por sua vez, regulam relaçóes interpessoais e conflitos entre atores que se reconhecem como membros de uma comunidade abstrata, criada por meio de normas do direito ${ }^{17}$.

Habermas inicia sua crítica à Jurisprudência dos Valores observando: "as reservas contra a legitimidade da jurisprudência do Tribunal Constitucional Federal não dependem apenas da mudança de paradigmas, mas também de concepçóes metodológicas" ${ }^{18}$.

15 HABERMAS, Direito e democracia I, p. 141.

16 HABERMAS, Direito e democracia I, p. 141.

17 HABERMAS, Direito e democracia I, p. 147.

18 HABERMAS, Direito e democracia I, p. 314. 
Essa afirmação volta-se à doutrina da ordem de valores desenvolvida pelo Bundesverfassungsgericht. A questão da legitimidade e competência emerge como pano de fundo da crítica à política de concretização de valores materiais constitucionais, sendo que tal ideia de realização de valores ultrapassaria a esfera de competência dos tribunais.

A crítica assume um viés de nítida importância a partir da distinçáo que Habermas "princípios ou normas mais elevadas" e valores, afirmando que "o verdadeiro problema reside na adaptação de princípios do direito a valores" ${ }^{19}$. Nesse aspecto, a ideia de concretização de valores pretensamente descobertos pelo direito constitucional é duramente criticada por Habermas, quando afirma que "nestes casos" o Tribunal pode tornar-se uma instância autoritária, eis que, no caso de colisão, todas as razóes poderiam se tornar relevantes, ${ }^{20}$ afigurando-se argumentativamente no meio jurídico, o que evidenciaria o rompimento para com a compreensão deontológica das normas e princípios jurídicos.

A decisão, por assim dizer, permanece dependente de critérios estranho à legislação democraticamente produzida, eis que os valores são construídos com base na própria inteligência do Tribunal. A afirmação de Habermas de que o Tribunal pode tornar-se uma instância autoritária diz respeito exatamente a esse aspecto, pois, afinal, os critérios balizadores da decisão judicial passariam a depender de uma racionalidade centrada tão somente no entendimento do Tribunal sobre essa pretensa ordem de valores, à revelia da realidade de, para utilizar a expressão de Dworkin ${ }^{21}$, "um sistema jurídico integro e coerente".

É por isso que o debate vai ao encontro da necessidade de uma jurisprudência orientada por princípios, então capaz de delimitar seus critérios de ação no caso de eventual conflito. Na esteira de Dworkin, Habermas afirma que:

[...] "normas validas formam uma estrutura relacional flexível, na qual as relaçóes podem deslocar-se segundo as circunstâncias de cada caso; porém esse deslocamento está sob a reserva da coerência, a qual garante que todas normas se ajuntam num sistema afinado, o qual admite para cada caso uma única solução correta”. 22

19 HABERMAS, Direito e democracia I, p. 316.

20 HABERMAS, Direito e democracia I, p. 321.

21 DWORKIN, Ronald. Uma questão de princípio. São Paulo: Martins Fontes, 2005. p. 239.

22 HABERMAS, Direito e democracia I, p. 323. Nesse aspecto, é igualmente interessante a tese de Dworkin sobre a historicidade, coerência e integridade do direito quando afirma que "decidir em casos controversos no direito é mais ou menos como esse estranho exercício literário. A similaridade é mais evidente quando os juízes examinam e decidem casos do Commom Law, isto é. Quando nenhuma lei ocupa posição central na questão jurídica e o argumento gira em torno de quais regras ou princípios do direito 'subjazem' a decisōes de outros juízes, no passado, sobre matéria semelhante. Cada juiz, então, é como um romancista na corrente. Ele deve ler tudo o que outros juízes escreveram no passado, não apenas para descobrir o que disseram, ou seu estado de espírito quando o disseram, mas para chegar a uma opiniấo sobre o que esses juízes fizeram coletivamente, da maneira como cada um de nossos romancistas formou uma opinião sobre o romance coletivo escrito até então. Qualquer juiz obrigado a decidir uma demanda descobrirá, se olhar nos livros adequados, registros de muitos casos plausivelmente similares, decididos há décadas ou mesmo 
Ademais, a Jurisprudência dos Valores aponta, inegavelmente, para o problema da legitimidade do Tribunal Constitucional.

\section{Conclusões}

A insurgência habermasiana contra a Jurisprudência dos Valores é foco de críticas de Streck, no sentido de um não enfraquecimento da democracia. $\mathrm{O}$ autor concorda que a jurisprudência da valoração assenta-se "nos quadros do paradigma da subjetividade"23, onde o texto legal demonstraria apenas o início de uma cadeia valorativa, sendo que tais valores deveriam ser descobertos pelo intérprete. Streck defende, portanto, a efetividade da jurisdição constitucional (em sua forma substancialista e republicana), deixando de aceitar qualquer espécie de decisionismo.

O problema da consideração de valores é justamente o fato de que o entendimento sobre a existência de uma pretensa ordem valorativa deságua no conhecido problema do ativismo judicial. A principal crítica de Habermas, contudo, centra-se em uma temida afronta à democracia.

O receio habermasiano funda-se, então, na tensão entre legislação e jurisprudência que passa a ter lugar quando da consideração de valores. Streck, contudo, condena a forma como essa metodologia da valoração foi apropriada pelos tribunais brasileiros. No caso do Brasil, houve uma equivocada recepção da tese dos valores, bem como igual incorreção no que tange ao entendimento da ponderação de valores proposta por Alexy.

A prática brasileira vale-se, entáo, do entendimento sobre uma pretensa ordem valorativa, bem como póe em prática uma equivocada ponderação de valores possibilitando, com isso, julgamentos arbitrários, voluntaristas e dissonantes para com a realidade (principiológica) constitucional, ou seja, a tese dos valores deságua em julgamentos subjetivistas e, por vezes, desconexos da realidade social.

\section{Referências}

ALFREDO, Garcia-Roza, Luiz Alfredo. Palavra e verdade na filosofia antiga e na psicanálise. Rio de Janeiro: Jorge Zahar Editor, 1990; Crátilo. Versão do grego, prefácio e notas do Pe. Dias Palmeira. Lisboa: Livraria Sá da Costa, 1994.

séculos por muitos outros juízes, de estilos e filosofias judiciais e políticas diferentes, em períodos nos quais o processo e as convençóes judiciais eram diferentes. Ao decidir o novo caso, cada juiz deve considerar-se como parceiro de um complexo empreendimento em cadeia, do qual essas inúmeras decisóes, estruturas, convençôes e práticas são a história; é seu trabalho continuar essa história no futuro por meio do que ele faz agora. Ele deve interpretar o que aconteceu antes porque tem a responsabilidade de levar adiante a incumbência que tem em mãos e não partir em alguma nova direção. Portanto, deve determinar, segundo seu próprio julgamento, o motivo das decisóes anteriores, qual realmente é, tomado como um todo, o propósito ou o tema da prática até então.” DWORKIN, Uma questão de princípio, p. 237-238.

23 STRECK, Verdade e consenso, p. 193. 
DWORKIN, Ronald. Uma questão de princípio. São Paulo: Martins Fontes, 2005.

GADAMER, Hans-Georg. Verdade e Método. Petrópolis. Editora: Vozes. 2 Ed.

HEIDEGGER, Martin. Introduçáo à filosofia. Tradução de Marco Antônio Casanova. São Paulo: Martins Fontes, 2008.

HEIDEGGER, (2007). In Griot - Revista de Filosofia v.6, n.2, dezembro/2012 ISSN 2178-1036 Notas sobre a interpretaçáo heideggeriana da subjetividade e do cogito cartesiano - Edgard Vinícius Cacho Zanette. Griot - Revista de Filosofia, Amargosa, Bahia - Brasil, v.6, n.2, dezembro/2012/ www.ufrb.edu.br/griot.

HABERMAS, Jürgen. Direito e democracia I. Rio de Janeiro.Tempo Brasileiro, 1997.

HECK, Philipp. El problema de la creación del derecho. Granada: Comares, 1999.

HECK, Philipp. Interpretação da lei e jurisprudência dos interesses. Trad. José Osório. São Paulo: Saraiva, 1948.

IHERING, Rudolf von. El fin en el derecho. Pamplona: Anacleta, 2005.

KAUFMANN, Arthur. HASSEMER, Winfried (Org.). Introduçáo à filosofia do direito e à teoria do direito contemporâneo. Lisboa: Fundação Calouste Gulbenkian, 2002.

KELSEN, Hans. Teoria pura do direito. São Paulo: Martins Fontes, 2000.

KRETSCHMANN, Ângela. História crítica do sistema jurídico: da prudência antiga à ciência moderna. Rio de Janeiro: Renovar, 2006.

KRUEGER, Paul. BERLIM Theodor Mommsen. BERLIM Hildesheim. Corpus iuris civilis. digestorum seu pandectarum pars prima. liber primus. (Corpo de direito civil. Primeira parte do digesto ou das pandectas. primeiro livro)(30 de Dezembro de 533), in : Corpus Iuris Civilis, Recognovit. Weidmann, 1872, Vol. 1.

LOSANO, Mario Giuseppe. Sistema e estrutura no direito. Volume 1: Das origens à escola histórica. São Paulo: Martins Fontes, 2008.

LOSANO, Mario Giuseppe. Sistema e estrutura no direito. Volume 2. O século XX. São Paulo: Martins Fontes, 2010.

OLIVEIRA, Manfredo Araújo. Reviravolta linguístico-pragmática na filosofia contemporânea. São Paulo: Ediçóes Loyola, 1996.

PLATÃO, ver as Obras Completas de Platáo. Trad. de Carlos Alberto Nunes. Belém: Universidade Federal do Pará, Coleção Amazônia - Série Farias Brito, 1980.

STEIN, Ernildo. Aproximaçóes sobre hermenêutica. Porto Alegre: Edipucrs, 1996.

STRECK, Lenio Luiz. Verdade e Consenso: constituição, hermenêutica e teorias discursivas. Ed.4 São Paulo, Saraiva, 2011. 
STRECK, Lenio Luiz. Hermenêutica jurídica $\mathbf{e}(\mathbf{m})$ crise: uma exploraçáo hermenêutica daconstruçấo do Direito. Ed. 11 rev., atual. e ampl. - Porto Alegre: Livraria do Advogado Editora, 2013.

STRECK, Lenio Luiz. Jurisdiçáo constitucional e decisáo jurídica. São Paulo: Editora Revista dos Tribunais, 2013. 